\title{
Effect of the Centrally Acting Muscle Relaxant Tizanidine on Spinal Reflexes: Involvement of Descending Noradrenergic Systems
}

\author{
Hideki Ono' ${ }^{1}$, Chiharu Fukushima ${ }^{1}$ and Hideomi Fukuda ${ }^{2}$ \\ 'Department of Toxicology and Pharmacology, Faculty of Pharmaceutical Sciences, University of Tokyo, Hongo 7-3-1, Bunkyo-ku, Tokyo 113, Japan \\ ${ }^{2}$ Department of Pharmacology, College of Pharmacy, Nihon University, 7-7-I Narashinodai, Funabashi, Chiba 274, Japan
}

Received December 16, 1992 Accepted April 30, 1993

\begin{abstract}
Experiments were performed on intact and spinalized rats anesthetized with urethane and $\alpha$ chloralose. In intact rats, administration of tizanidine $(0.1 \mathrm{mg} / \mathrm{kg}$, i.v.) decreased the mono- (MSR) and polysynaptic reflex potentials (PSR). Blood pressure was initially elevated and then lowered by tizanidine. Although pretreatments with hexamethonium and phentolamine prevented the tizanidine-induced decrease in blood pressure, the depressant effects of tizanidine on the reflexes remained. The $\alpha_{2}$-antagonist idazoxan inhibited the tizanidine-induced decrease in spinal reflexes, suggesting that central $\alpha_{2}$-adrenoceptors are involved in the depression of the reflexes. In spinalized rats, tizanidine transiently increased the MSR and gradually decreased the PSR. Blood pressure was elevated transiently by tizanidine. Although the hypertensive effect of tizanidine was inhibited by phentolamine, the effect of tizanidine on the PSR did not change. Prazosin blocked the stimulatory effect of tizanidine on the MSR and caused a rapid decrease of the PSR, suggesting that spinal $\alpha_{1}$-adrenoceptors are involved in the enhancement of the reflexes. These results suggest that the depressant effects of tizanidine on spinal reflexes are due to the supraspinal and spinal effects of the drug, and not to changes in blood pressure.
\end{abstract}

Keywords: Tizanidine, Noradrenergic, Muscle relaxant, Spinal reflex, Blood pressure

Descending noradrenergic systems in the spinal ventral horn are considered to be mainly facilitatory to spinal motoneurons via $\alpha_{1}$-adrenoceptors (1). Tizanidine is a centrally acting muscle relaxant $(2,3)$ that has a similar structure to that of clonidine, a centrally acting hypotensive agent. In non-spinalized rats which have an intact connection between the brain and the spinal cord, tizanidine depressed the mono- (MSR) and polysynaptic reflexes (PSR) (3). Since tizanidine is an $\alpha_{2}$-agonist which can stimulate noradrenergic autoreceptors, tizanidine is suggested to reduce the activity of descending noradrenergic neurons at the supraspinal level, and consequently inhibit the tonically facilitated state of reflex activity. However, since tizanidine lowers blood pressure in intact rats, it is possible that the effects of tizanidine on spinal reflexes are secondary to the changes in blood pressure.

In the present study, the effects of tizanidine on spinal reflexes and blood pressure were studied, and it was shown that effects of this drug on the reflexes are due to CNS effects which are not secondary to peripheral changes in blood pressure.

\section{MATERIALS AND METHODS}

\section{Recording of MSR and PSR}

Male Wistar rats, weighing $300-400 \mathrm{~g}$, were anesthetized with urethane $(1 \mathrm{~g} / \mathrm{kg}$, i.p.) and $\alpha$-chloralose (25 $\mathrm{mg} / \mathrm{kg}$, i.p.) and then artificially ventilated. Both intact and spinalized preparations were used. In the case of the spinalized preparation, the bilateral vagus nerves were severed at the cervical region to avoid any parasympathetic effect on the heart, and the spinal cord was transected at the $\mathrm{C} 1$ level. Laminectomy was performed in the lumbosacral region. The ventral and dorsal roots below $\mathrm{L} 4$ were cut bilaterally, and the dorsal and ventral roots of segments L4 and L5 were isolated. A skin pouch was formed at the site of the dissection so that the exposed tissues could be covered with liquid paraffin kept at $36 \pm 0.5^{\circ} \mathrm{C}$. Rectal temperature was maintained at $36 \pm 0.5^{\circ} \mathrm{C}$ by a heating pad. The dorsal and ventral roots of segment L5 were placed on bipolar silver-silver chloride wire electrodes for stimulation $(0.2 \mathrm{~Hz}, 0.05 \mathrm{msec}$, supramaximal) and recording, respectively. The reflex potentials were amplified (AVB-10, Nihon Kohden, Tokyo), displayed on an 
oscilloscope (VC-10, Nihon Kohden) and averaged 8 times by an averaging computer (DAT-1100, Nihon Kohden), the analog output of which was recorded by a recorder (FBR-252A, Toa, Tokyo). The amplitudes of MSR and PSR, which has a latency corresponding to the disynaptic reflex, were then measured (Fig. 1). In intact rats, the amplitude of the MSR was $0.5-1.2 \mathrm{mV}$ and that of the PSR was $0.2-0.5 \mathrm{mV}$. The PSR amplitude of the spinalized rats was lower than that of the intact rats. The latency of the MSR was 1.8-2.2 msec depending on the stimulating and recording sites of the roots, and the delay of the PSR peak from the MSR peak was 0.8-1.0 msec.

\section{Blood pressure}

Blood pressure in the femoral artery was monitored with a transducer (model 800, Bentley Trantec, Irvine, CA, USA) and recorded on a polygraph (RM-25, Nihon Kohden).

\section{Drug treatment}

Rats were pretreated with several drugs. Hexamethonium $\mathrm{Br}(10 \mathrm{mg} / \mathrm{kg})$, idazoxan $(0.5 \mathrm{mg} / \mathrm{kg})$, phentolamine mesylate $(2 \mathrm{mg} / \mathrm{kg})$ and prazosin- $\mathrm{HCl}(1 \mathrm{mg} / \mathrm{kg})$ were administered intravenously 10 or $15 \mathrm{~min}$ before injection of tizanidine- $\mathrm{HCl}(0.1 \mathrm{mg} / \mathrm{kg}$, i.v. $)$.
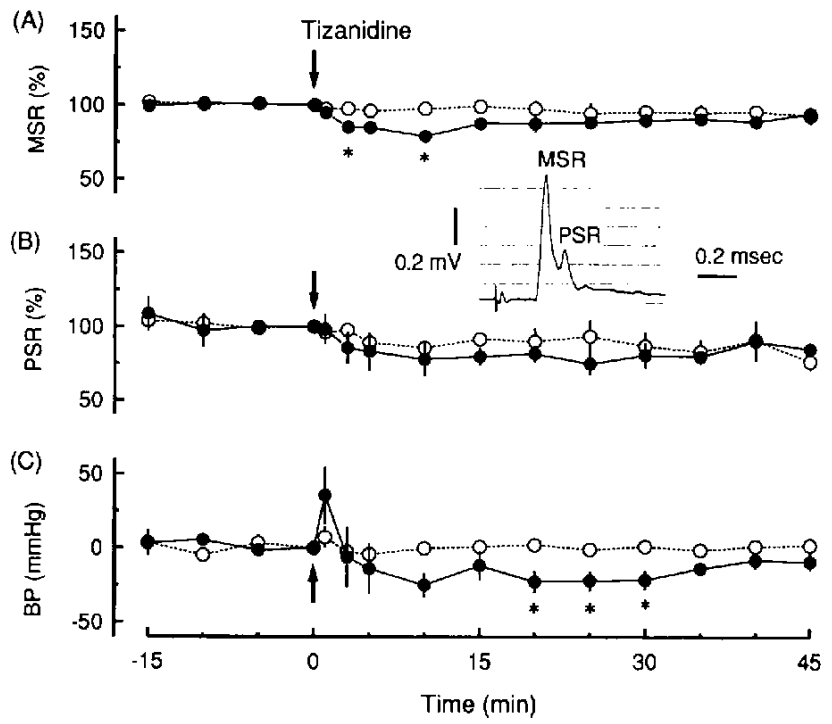

Fig. 1. Effect of tizanidine-HCl on the MSR (A), the PSR (B) and blood pressure $(C)$ in intact rats. Abscissa: time after injection of tizanidine. Ordinates: relative reflex amplitude $(\%)(A, B)$ and blood pressure change (delta $\mathrm{mmHg}$ ). Each point represents the mean \pm S.E.M. of 4 separate experiments as a percentage of the value $(A, B)$ or change in blood pressure (C) at time 0 . Where S.E.M. bars are not shown, they lie within the dimensions of the symbols. Open circles: saline. Solid circles: tizanidine- $\mathrm{HCl}, 0.1 \mathrm{mg} / \mathrm{kg}$, i.v. ${ }^{*} \mathrm{P}<0.05$ : two-tailed Student's $t$-test or Welch's procedure. Insert shows a sample record of reflex potentials.

\section{Drugs}

Drugs used were tizanidine- $\mathrm{HCl}$ (Sandoz, Basle, Switzerland), hexamethonium Br (Yamanouchi, Tokyo), idazoxan (Reckitt \& Colman, Hull, Yorkshire, UK), phentolamine mesylate (Regitin Injection, Ciba Geigy, Takarazuka) and prazosin- $\mathrm{HCl}$ (Pfizer, Groton, CT, USA). Prazosin- $\mathrm{HCl}$ was dissolved in distilled water. Other drugs were dissolved in physiological saline.

\section{Statistics}

Student's $t$-test (two-tailed) was employed to compare control values with treated values. When the population variances were unequal, Welch's procedure was employed.

\section{RESULTS}

\section{Effects of tizanidine in intact rats}

In the previous study, $0.01-0.3 \mathrm{mg} / \mathrm{kg}$, i.v. tizanidine$\mathrm{HCl}$ inhibited the MSR, but higher doses of 1 and 5 $\mathrm{mg} / \mathrm{kg}$ did not inhibit the MSR in intact rats. PSR was inhibited by $0.01-5 \mathrm{mg} / \mathrm{kg}$ tizanidine- $\mathrm{HCl}$ (3). Therefore in the present study, $0.1 \mathrm{mg} / \mathrm{kg}$ tizanidine- $\mathrm{HCl}$ was used to observe a consistent depression of both MSR and PSR. Tizanidine- $\mathrm{HCl}(0.1 \mathrm{mg} / \mathrm{kg}$, i.v.) caused about a $20 \%$ reduction in the amplitude of the MSR and PSR (Fig. 1,
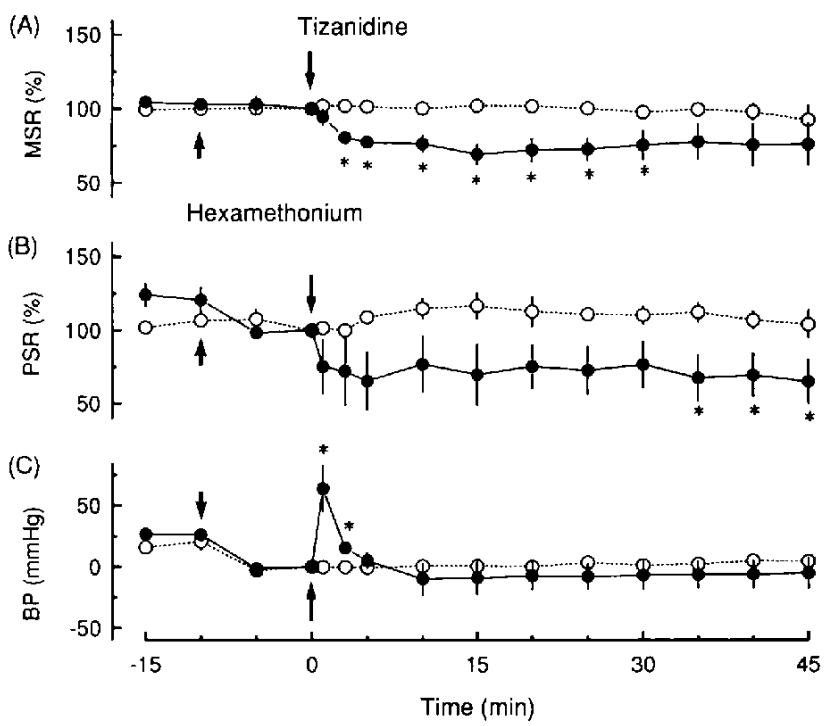

Fig. 2. Effect of tizanidine-HCl on the MSR (A), the PSR (B) and blood pressure $(C)$ in hexamethonium-treated intact rats. Abscissa: time after injection of tizanidine. Ordinates: relative reflex amplitude (\%) (A, B) and blood pressure change (delta $\mathrm{mmHg}$ ). Each point represents the mean \pm S.E.M. of 4 separate experiments as a percentage of the value (A, B) or change in blood pressure (C) at time 0. Open circles: hexamethonium $\mathrm{Br}, 10 \mathrm{mg} / \mathrm{kg}$, i.v. + saline. Solid circles: hexamethonium + tizanidine- $\mathrm{HCl}, 0.1 \mathrm{mg} / \mathrm{kg}$, i.v. ${ }^{*} \mathrm{P}<0.05$ : two-tailed Student's $t$-test or Welch's procedure. 
A and B) without affecting those latencies. The effect of tizanidine on blood pressure was biphasic; tizanidine transiently elevated $(30 \mathrm{mmHg}$ ) and then lowered $(25 \mathrm{mmHg})$ the mean blood pressure (Fig. 1C). The effects of tizanidine recovered to the control level $45 \mathrm{~min}$ after injection.

Effects of acute hypotension on the spinal reflexes were then studied. The ganglion blocker hexamethonium $\mathrm{Br}$ ( $10 \mathrm{mg} / \mathrm{kg}$, i.v.), which cannot cross the blood-brain barrier, alone reduced the blood pressure to about $50 \mathrm{mmHg}$ (25 $\mathrm{mmHg}$ reduction) (Fig. $2 \mathrm{C}$ ). Hexamethonium alone did not reduce the MSR (Fig. $2 \mathrm{~A}$ ). In the presence of hexamethonium, tizanidine effectively inhibited the MSR and the PSR (Fig. 2, A and B). Because of the lowering of blood pressure, the hypertensive effect of tizanidine was facilitated by hexamethonium (Fig. 2C). Thus the depressant effects of tizanidine on the spinal reflex are not due to the hypotension produced by the drug.

Pretreatment with the $\alpha$-antagonist phentolamine mesylate $(2 \mathrm{mg} / \mathrm{kg}$, i.v.) lowered the blood pressure to about $50 \mathrm{mmHg}$ (25 mmHg reduction) (Fig. 3C). However the MSR and the PSR were not reduced by phentolamine. In the presence of phentolamine, tizanidine effectively reduced the amplitude of the MSR and the PSR, but did not elevate or lower the blood pressure (Fig. 3). These results suggest that hypotension or hypertension caused by tizanidine is not a causal factor in the depression of spi-
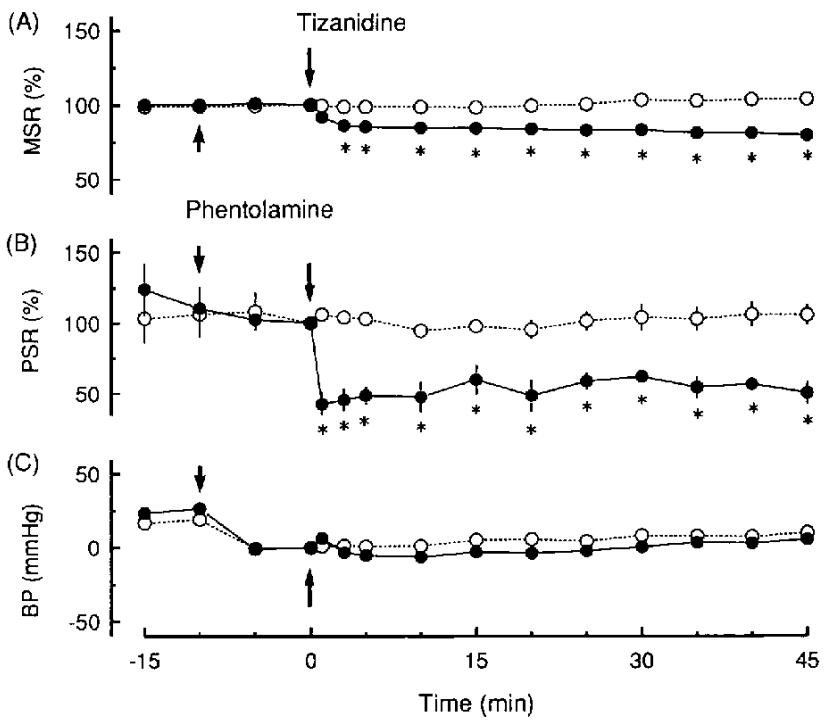

Fig. 3. Effect of tizanidine-HCl on the MSR (A), the PSR (B) and blood pressure $(C)$ in phentolamine-treated intact rats. Abscissa: time after injection of tizanidine. Ordinates: relative reflex amplitude $(\%)(\mathrm{A}, \mathrm{B})$ and blood pressure change (delta $\mathrm{mmHg}$ ). Each point represents the mean \pm S.E.M. of 4 separate experiments as a percentage of the value $(A, B)$ or change in blood pressure $(C)$ at time 0 . Open circles: phentolamine mesylate, $2 \mathrm{mg} / \mathrm{kg}$, i.v. + saline. Solid circles: phentolamine + tizanidine $-\mathrm{HCl}, \quad 0.1 \mathrm{mg} / \mathrm{kg}$, i.v. ${ }^{*} \mathbf{P}<0.05$ : two-tailed Student's $t$-test or Welch's procedure. nal reflexes.

The $\alpha_{2}$-antagonist idazoxan $(0.5 \mathrm{mg} / \mathrm{kg}$, i.v.) alone increased the MSR but did not affect the PSR or blood pressure (Fig. 4). In the presence of idazoxan, tizanidine did not inhibit MSR or PSR potential, and it did not lower the blood pressure (Fig. 4). These results suggest that the inhibitory effect of tizanidine on the spinal reflex is due to its effect on central $\alpha_{2}$-receptors which modulate spinal reflexes and blood pressure.

\section{Effects of tizanidine in spinalized rats}

The mean blood pressure of spinalized rats was around $50 \mathrm{mmHg}$. This low level is due to the reduction of descending facilitatory tone on the peripheral cardiovascular system. Tizanidine- $\mathrm{HCl}(0.1 \mathrm{mg} / \mathrm{kg}$, i.v. $)$ transiently increased the MSR (Fig. 5A). PSR was decreased gradually by tizanidine (Fig. 5B). Blood pressure was strongly elevated by tizanidine ( $90 \mathrm{mmHg}$ elevation) (Fig. $5 \mathrm{C}$ ).

The effect of tizanidine on the PSR was not changed by pretreatment with phentolamine mesylate $(2 \mathrm{mg} / \mathrm{kg}$, i.v.) (Fig. 6), although the elevation of blood pressure was reduced strongly by phentolamine ( $25 \mathrm{mmHg}$ elevation). These results suggest that the change in the PSR caused by tizanidine is not due to a transient increase in blood pressure.

The $\alpha_{1}$-antagonist prazosin- $\mathrm{HCl}(1 \mathrm{mg} / \mathrm{kg}$, i.v.) abol-
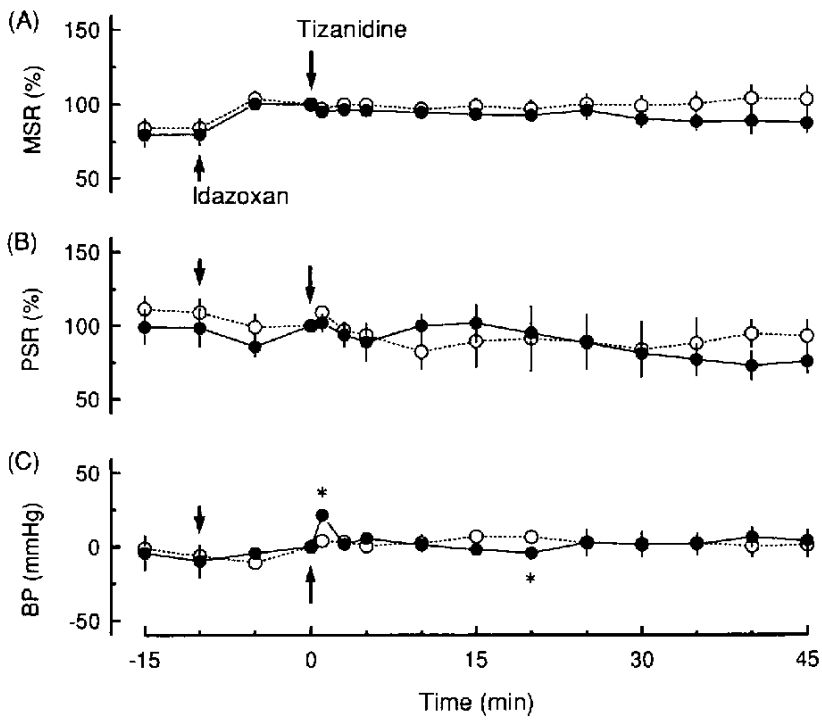

Fig. 4. Effect of tizanidine-HCl on the MSR (A), the PSR (B) and blood pressure $(C)$ in idazoxan-treated intact rats. Abscissa: time after injection of tizanidine. Ordinates: relative reflex amplitude $(\%)$ (A, B) and blood pressure change (delta $\mathrm{mmHg}$ ). Each point represents the mean \pm S.E.M. of 4 separate experiments as a percentage of the value $(A, B)$ or change in blood pressure $(C)$ at time 0 . Open circles: idazoxan, $0.5 \mathrm{mg} / \mathrm{kg}$, i.v. + saline. Solid circles: idazoxan + tizanidine- $\mathrm{HCl}, 0.1 \mathrm{mg} / \mathrm{kg}$, i.v. ${ }^{*} \mathrm{P}<0.05$ : two-tailed Student's $t$-test or Welch's procedure. 

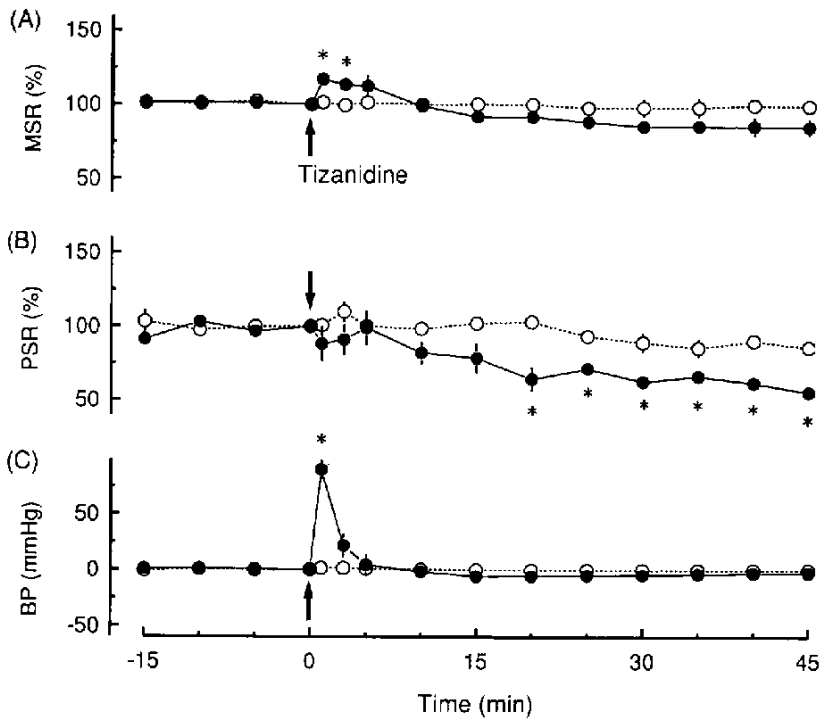

Fig. 5. Effect of tizanidine-HCl on the MSR (A), the PSR (B) and blood pressure $(C)$ in spinalized rats. Abscissa: time after injection of tizanidine. Ordinates: relative reflex amplitude $(\%)(A, B)$ and blood pressure change (delta $\mathrm{mmHg}$ ). Each point represents the mean \pm S.E.M. of 4 separate experiments as a percentage of the value $(A, B)$ or change in blood pressure (C) at time 0 . Open circles: saline. Solid circles: tizanidine- $\mathrm{HCl}, 0.1 \mathrm{mg} / \mathrm{kg}$, i.v. ${ }^{*} \mathrm{P}<0.05$ : twotailed Student's $t$-test or Welch's procedure.
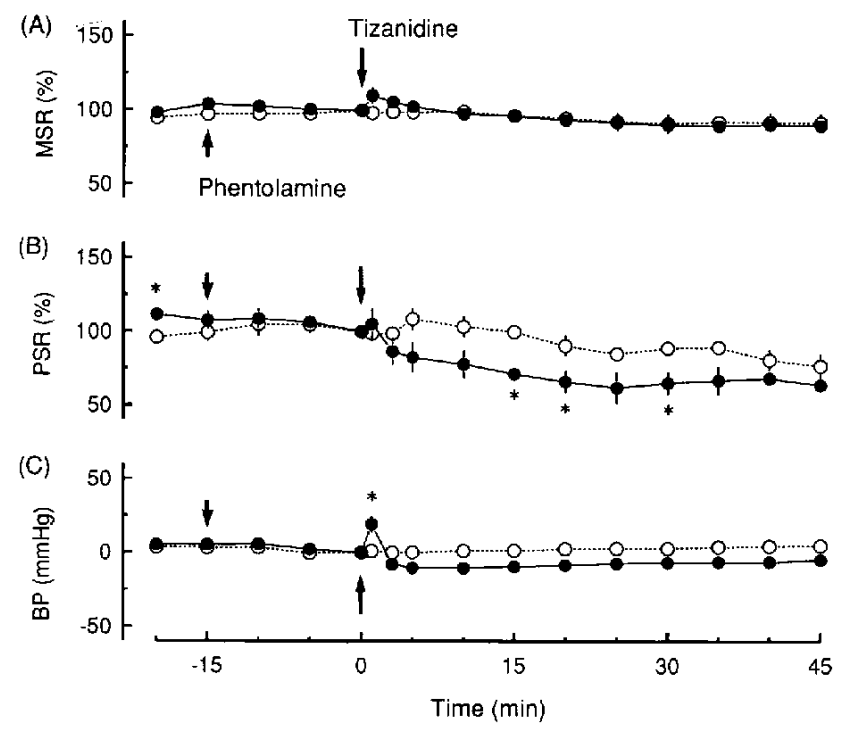

Fig. 6. Effect of tizanidine-HCl on the MSR (A), the PSR (B) and blood pressure $(C)$ in phentolamine-treated spinalized rats. Abscissa: time after injection of tizanidine. Ordinates: relative reflex amplitude $(\%)(\mathrm{A}, \mathrm{B})$ and blood pressure change (delta $\mathrm{mmHg}$ ). Each point represents the mean \pm S.E.M. of 4 separate experiments as a percentage of the value $(A, B)$ or change in blood pressure $(C)$ at time 0 . Open circles: phentolamine mesylate, $2 \mathrm{mg} / \mathrm{kg}$, i.v. + saline. Solid circles: phentolamine + tizanidine- $\mathrm{HCl}, \quad 0.1 \mathrm{mg} / \mathrm{kg}$, i.v. ${ }^{*} \mathbf{P}<0.05$ : two-tailed Student's $\boldsymbol{t}$-test or Welch's procedure.
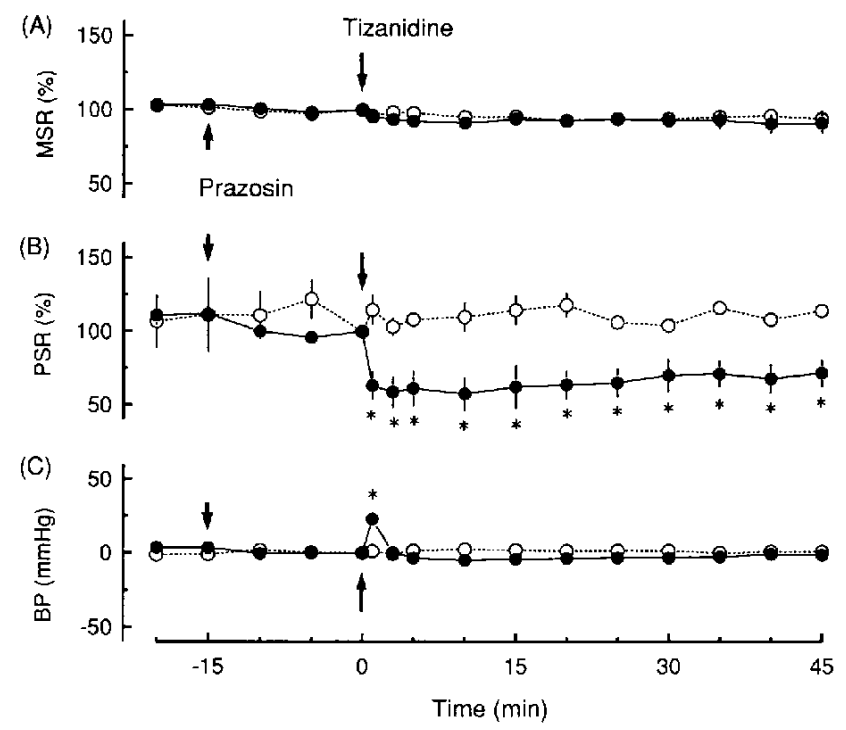

Fig. 7. Effect of tizanidine-HCl on the MSR (A), the PSR (B) and blood pressure $(C)$ in prazosin-treated spinalized rats. Abscissa: time after injection of tizanidine. Ordinates: relative reflex amplitude $(\%)$ (A, B) and blood pressure change (delta $\mathrm{mmHg}$ ). Each point represents the mean \pm S.E.M. of 4 separate experiments as a percentage of the value $(A, B)$ or change in blood pressure $(C)$ at time 0. Open circles: prazosin-HCl $1 \mathrm{mg} / \mathrm{kg}$, i.v. + saline. Solid circles: prazosin + tizanidine- $\mathrm{HCl}, 0.1 \mathrm{mg} / \mathrm{kg}$, i.v. ${ }^{*} \mathrm{P}<0.05$ : twotailed Student's $t$-test or Welch's procedure.

ished the stimulatory effect of tizanidine on the MSR (Fig. 7A). Pretreatment with prazosin caused a rapid and strong inhibition of the depressant effect of tizanidine on the PSR (Fig. 7B). Elevation of blood pressure was inhibited by prazosin to a degree similar to that caused by phentolamine (Figs. 5C, 6C and $7 \mathrm{C}$ ). These results suggest that at the spinal cord level, tizanidine transiently increases the MSR and the PSR, and then inhibits the PSR.

\section{DISCUSSION}

In intact rats, tizanidine $(1 \mathrm{mg} / \mathrm{kg}$, i.v.) inhibited the MSR and the PSR, and it changed the blood pressure (Fig. 1). The possibility has been considered that changes in the reflex amplitude caused by tizanidine are secondary to the change in blood pressure. The hypotensive effect of tizanidine was masked by pretreatments with hexamethonium and phentolamine (Figs. $2 \mathrm{C}$ and $3 \mathrm{C}$ ), both of which have apparent difficulty in penetrating the blood-brain barrier. The hypertensive effects of tizanidine were antagonized by phentolamine (Fig. $3 \mathrm{C}$ ). In the presence of hexamethonium or phentolamine, tizanidine inhibited the MSR and the PSR in intact rats (Figs. 2A, B and 3A, B). In spinalized rats, tizanidine transiently increased the MSR, gradually decreased the PSR and strongly elevated the blood pressure (Fig. 5). Phentolamine decreased the 
elevation of the blood pressure caused by tizanidine (Fig. 6). These results suggest that the changes in the reflex caused by tizanidine are independent of the peripheral change in blood pressure, and that the spinal reflex potentials are relatively resistant to changes in blood pressure. Our previous study showed that prazosin but not phentolamine inhibited the MSR-stimulating effects of methamphetamine, which releases noradrenaline from noradrenergic terminals (4), suggesting that phentolamine has difficulty in penetrating the blood-brain barrier.

The locus coeruleus, a large pontine noradrenergic nucleus which projects to many brain regions, also projects to the ventral horn of the spinal cord $(5,6)$. Electrical stimulation of the locus coeruleus facilitates the MSR in the lumbar spinal cord in cats $(7,8)$ and rats $(9$, 10). MSR potentiation evoked by locus coeruleus stimulation is blocked by chlorpromazine or phenoxybenzamine $(7,10)$. Therefore, $\alpha_{1}$-adrenoceptors are involved in the MSR potentiation. In non-spinalized rats, in which there is an intact connection between the brain and the spinal cord, tizanidine $(0.1 \mathrm{mg} / \mathrm{kg}$, i.v.) depressed the MSR and the PSR (Fig. 1), and the depression was blocked by the $\alpha_{2}$-antagonist idazoxan (Fig. 4). In radio frequencylesioned rigidity, 4th ventricularly administered but not intrathecally administered tizanidine reduced the rigidity, and the reduction was blocked by the $\alpha_{2}$-antagonist piperoxane (11). In a noradrenaline release study using anesthetized rats, tizanidine- $\mathrm{HCl}(0.1$ and $0.3 \mathrm{mg} / \mathrm{kg}$, i.v.) and clonidine- $\mathrm{HCl}(0.03$ and $0.1 \mathrm{mg} / \mathrm{kg}$, i.v. $)$ inhibited the release of noradrenaline from the spinal cord, and the inhibitory effect of clonidine was antagonized by the $\alpha_{2}$-antagonist piperoxane (12). These results suggest that tizanidine affects supraspinal $\alpha_{2}$-receptors and inhibits the spinal reflexes by reducing the tonically active noradrenergic facilitatory tone to the spinal cord. However, involvement of imidazoline-preferring receptors in the effects of tizanidine and idazoxan cannot be excluded $(13,14)$.

In spinal cord slices isolated from adult rats, motoneuron excitability was increased by noradrenaline and clonidine via $\alpha_{1}$-adrenoceptors, and in the presence of prazo$\sin$, motoneuron excitability was decreased by $\alpha$-agonists (15). In spinalized rats, tizanidine slightly increased the MSR and inhibited the PSR (Figs. 5 and 6). In the presence of prazosin, tizanidine slightly inhibited the MSR and strongly inhibited the PSR (Fig. 7). In a previous study, the inhibitory effects of tizanidine, clonidine and L-dopa in prazosin-treated rats were antagonized by the $\alpha_{2}$-antagonist piperoxane (16). These results suggest that spinal $\alpha_{1}$-adrenoceptors mediate the enhancement of the MSR and PSR, that spinal $\alpha_{2}$-adrenoceptors mediate the slight depression of the MSR and profound depression of the PSR, and that $\alpha_{1}$-agonistic action is dominant in the effects of $\alpha$-agonists on motoneurons.
In summary, tizanidine is considered to inhibit spinal reflexes by stimulating $\alpha_{2}$-adrenoceptors at both the supraspinal and spinal levels. The spinal reflexes are relatively resistant to acute changes in blood pressure.

\section{Acknowledgments}

This work was supported in part by a Grant-in-Aid for Scientific Research from the Ministry of Education, Science and Culture, Japan. We thank Sandoz, Reckitt \& Colman and Pfizer for providing tizanidine- $\mathrm{HCl}$, idazoxan and prazosin- $\mathrm{HCl}$, respectively.

\section{REFERENCES}

1 Fukuda, H. and Ono, H.: Control of spinal motor system by descending noradrenergic neuron. Folia Pharmacol. Japon. 96, 1-9 (1990) (Abs. in English)

2 Sayers, A.C., Bürki, H. and Eichenberger, E.: The pharmacology of 5-chloro-4-(2-imidazolin-2-yl-amino)-2,1,3-benzothiadiazole (DS 103-282), a novel myotonolytic agent. Arzneimittelforschung 30, 793-803 (1980)

3 Ono, H., Matsumoto, K., Kato, K., Kato, F., Miyamoto, M., Mori, T., Nakamura, T., Oka, J. and Fukuda, H.: Effects of tizanidine, a centrally acting muscle relaxant, on motor systems. Gen. Pharmacol. 17, 137-142 (1986)

4 Ono, H., Ito, H. and Fukuda, H.: 2-Phenylethylamine and methamphetamine enhance the spinal monosynaptic reflex by releasing noradrenaline from the terminals of descending fibers. Japan. J. Pharmacol. 55, 359-366 (1991)

5 Nygren, L-.G. and Olson, L.: A new major projection from locus coeruleus: The main source of noradrenergic nerve terminals in the ventral and dorsal columns of the spinal cord. Brain Res. 132, 85-93 (1977)

6 Björklund, A. and Skagerberg, G.: Descending monoaminergic projections to the spinal cord. In Brain Stem Control of Spinal Mechanisms, Edited by Sjölund, B. and Björklund, A., pp. 55-88, Elsevier Biomedical Press, Amsterdam (1982)

7 Strahlendorf, J.C., Strahlendorf, H.K., Kingsley, R.E., Gintautas, J. and Barnes, C.D.: Facilitation of the lumbar monosynaptic reflexes by locus coeruleus stimulation. Neuropharmacology 19, 225-230 (1980)

8 Fung, S. and Barnes, C.D.: Evidence of facilitatory coerulospinal action in lumbar motoneurons of cats. Brain Res. 216, 299-311 (1981)

9 Chan, S. and Barnes, C.D.: Facilitation of lumbar monosynaptic reflexes by locus coeruleus in the rat. Brain Res. 369, $103-109$ (1986)

10 Hino, M., Ono, H. and Fukuda, H.: Involvement of noradrenergic systems in the effects of conditioning stimulation of the lower brain stem on the lumbar spinal reflex in rats. Gen. Pharmacol. 18, 41-45 (1987)

11 Nakamura, T., Ono, H. and Fukuda, H.: Effects of alpha $2^{-}$ agonists and alpha $a_{1}$-antagonists on the radio frequency-lesioned intercollicular decerebrate rigidity. Japan. J. Pharmacol. 40, Supp. 62P (1986)

12 Ono H., Satoh, M. and Fukuda, H.: $\alpha_{2}$-Agonist-induced reduction of noradrenaline release from descending noradrenergic terminals in rat spinal cord: functional relation to spinal motor system. Biomed. Res. 9, 169-176 (1988)

13 Muramatsu, I. and Kigoshi, S.: Tizanidine may discriminate 
between imidazoline-receptors and $\alpha_{2}$-adrenoceptors. Japan. J. Pharmacol. 59, 457-459 (1992)

14 Michel, M.C. and Ernsberger, P.: Keeping an eye on the I site: imidazoline-preferring receptors. Trends Pharmacol. Sci. 13, $369-370$ (1992)

15 Hirayama, T., Ono, H. and Fukuda, H.: Effects of adrenergic agents on ventral horn cells in rat spinal cord slices. Biomed. Res. 9, 343-351 (1988)

16 Tanabe, M., Ono, H. and Fukuda, H.: Spinal $\alpha_{1^{-}}$and $\alpha_{2^{-}}$ adrenoceptors mediate facilitation and inhibition of spinal motor transmission, respectively. Japan J. Pharmacol. 54, 77-85 (1990) 